\title{
Design and Performance Analysis of Coreless Axial-Flux Permanent-Magnet Generator for Small Wind Turbines
}

\author{
Dae-Won Chung* and Yong-Min You \\ Department of Electrical Engineering, Honam University, Gwangju 507-714, Korea
}

(Received 27 January 2014, Received in final form 22 June 2014, Accepted 1 July 2014)

\begin{abstract}
This paper presents an innovative design for a low-speed, direct-drive, axial-flux permanent-magnet (AFPM) generator with a coreless stator and rotor that is intended for application to small wind turbine power generation systems. The performance of the generator is evaluated and optimized by means of comprehensive 3D electromagnetic finite element analysis. The main focus of this study is to improve the power output and efficiency of wind power generation by investigating the electromagnetic and structural features of a coreless AFPM generator. The design is validated by comparing the performance achieved with a prototype. The results of our comparison demonstrate that the proposed generator has a number of advantages such as a simpler structure, higher efficiency over a wide range of operating speeds, higher energy yield, lighter weight and better power utilization than conventional machines. It would be possible to manufacture low-cost, axial-flux permanent-magnet generators by further developing the proposed design.
\end{abstract}

Keywords : axial-flux permanent-magnet (AFPM), coreless stator, direct-drive wind power generator, low speed, design optimization

\section{Introduction}

There is currently considerably increased interest in permanent-magnet (PM) generators for use with small wind turbines because they are compact, highly efficient, reliable and self-excited. Power generation from the wind primarily converts energy from the wind into mechanical energy through the rotating blades of a wind turbine, and uses the converted mechanical energy to drive a generator to produce electrical energy. The overall performance of a wind power generation system is thus very dependent on the conversion efficiency of its power generator $[1,2]$.

The axial-flux configuration of a PM generator, with its disc-type geometry, is easier to integrate into a wind turbine that is designed for low-speed applications, in comparison with its radial-flux counterpart. An axial-flux PM generator (AFPMG) uses high-strength, permanent magnets to create a magnetic field in the rotor. As there is no electrical current flowing to the rotor, there is no need for brushes, which improves reliability. In addition, AFPMGs can operate at different rotational speeds, so

CThe Korean Magnetics Society. All rights reserved.

*Corresponding author: Tel: +82-62-940-5494

Fax: +82-62-940-5053, e-mail: dwchung@honam.ac.kr manufacturers can design wind turbine drivetrains around their preferred topologies, possibly using a one- or twostage gearbox for medium speeds, or even removing the gearbox altogether to further improve reliability. The electromagnetic concept of a coreless AFPMG is similar to that of a radial-flux generator, but the lack of an iron core removes the attractive forces between the rotor and stator. The absence of these forces reduces the structural loads on the generator, so that considerable weight savings can be realized, even at higher power ratings. As a result of this lower structural load and lack of iron core, the coreless configuration eliminates all ferromagnetic material including the steel laminations that would otherwise be needed in the stator, and so does not incur any associated eddy current or hysteresis core losses. By eliminating the core losses, a coreless-stator AFPMG machine can operate at a higher efficiency than a conventional machine [3-5].

In the literature, an AFPM motor with a coreless stator and a Halbach-magnet array rotor with no back irons have been designed to drive a solar-powered electric vehicle at a higher efficiency of $96.5 \%$ at the rated power output and at an extremely high-power density [6]. A plastic multi-disc coreless AFPM motor was proposed to directly drive the propeller of a stratospheric unmanned aircraft because of its high efficiency over a wide power 
range and impressively low weight $[7,8]$. Coreless AFPM machines are also contenders for many power generation applications, particularly direct-drive designs, over a wide range of operating speeds. For instance, coreless AFPM generators have been investigated for application to lowspeed, direct-coupled wind turbine generators [9], mediumspeed applications such as automotive generators [10], and high-speed, direct-coupled gas turbine generators for aerospace applications [11, 12]. However, research into low-speed AFPM generators for application to low-cost power platforms is a relatively recent development [13]. To the best of our knowledge, the design and modeling of a low-speed, modular, direct-drive AFPM generator with a coreless stator and rotor for wind turbine power generation has not been reported yet.

This paper proposes a systematic optimal design methodology for an axial-flux permanent-magnet brushless machine with a coreless stator and rotor for use with small wind turbines. Both analytical and electromagnetic 3-dimensional finite element analysis (3D FEA) models are employed to calculate the parameters of the machine and to further analyze and optimize the generator's performance. Finally the design and fabrication of a prototype are described for testing and to demonstrate how design will be relatively simple to manufacture.

\section{Design of AFPM Generator}

\subsection{Design Strategy}

The proposed generator has double-disc configuration with two identical rotor discs (field) and a single stator disc (armature), as shown in Fig. 1. Both the rotor and the stator are coreless in which they have non-ferromagnetic cores. The single stator disc is fixed to the frame and is the stationary part of the machine. The stator coil is a three-phase, single-layer trapezoidal winding. This is embedded in a resin or plastic with a high mechanical strength to form a single stator disc. Similarly, the rotor

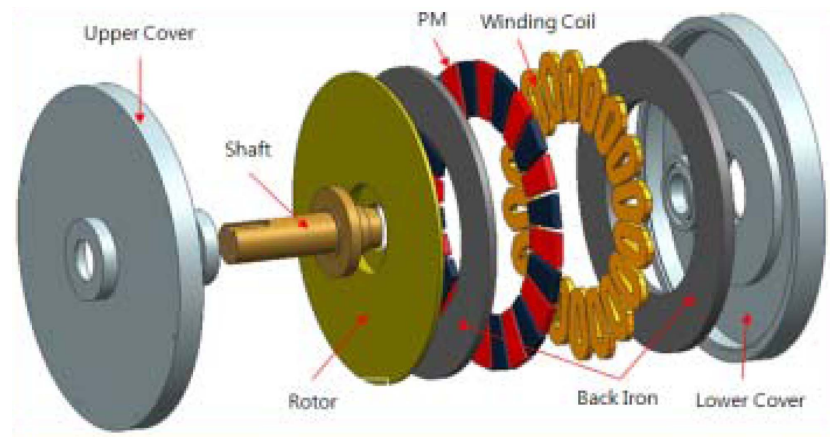

Fig. 1. (Color online) Basic structure of coreless AFPM machine. discs, consisting of NdFeB rare-earth PMs supported by a non-magnetic (aluminum or plastic) structure, constitute the rotating part which is directly connected to the shaft. This design does not incorporate any ferromagnetic material in its core and therefore does not incur any cogging torque effect or any core losses. The basic structure of the coreless AFPM machine is shown in Fig. 1.

From the view-point of standardizing AFPM generator manufacturing, the size and physical dimensions of the motor are the most important factors affecting the machine's performance and manufacturing cost. For this application, the design of the generator has to offer higher efficiency and power outputs despite the physical constraints, through minor modifications to the materials and components, in order to avoid performance challenges and to reduce development cost. Modern computer-aided design is used to optimize the design parameters for the following reasons [20]:

- The calculation of the design parameters and the evaluation of performance are combined and linked to a large number of options that are characterized by small changes to the parameters.

- The ability to perform very detailed electromagnetic and mechanical analysis allows us to confidently stretch the design to its limits, and avoid the need for a prototyping and test program that would be expensive and time-consuming.

Figure 2 shows the design flow and process using Maxwell 2D/3D ${ }^{\circledR}$ [14]. In the early stages of the design process, there is a need for strong iteration between the design requirements and the design outputs.

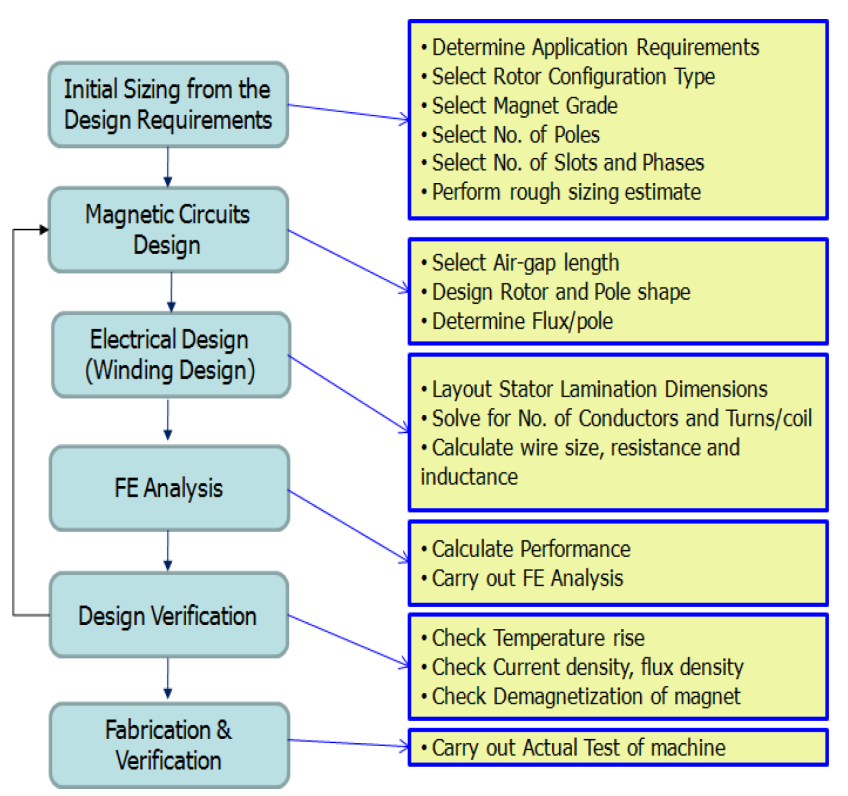

Fig. 2. (Color online) Flow of computer-aided design. 


\subsection{Analytical Design Approach}

\subsubsection{Rotor PM Design}

The magnetic design model is based on the double-disc, 24-poles AFPM shown in Fig. 3, which is used to calculate the parameters for the machine and to further analyze and optimize the machine's performance. The magnetic flux flows straight across the air-gaps between the stator and the rotor. The total flux through the same area of the magnet surfaces is unchanged and the air-gap

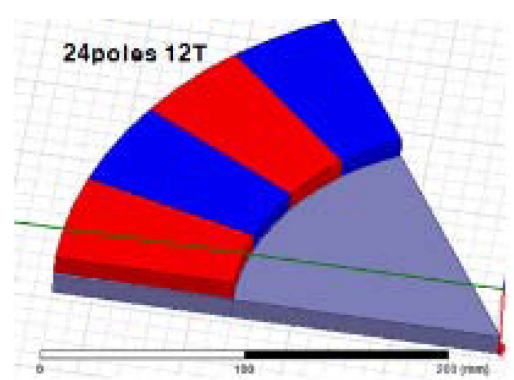

(a) $1 / 6$ section of rotor disc

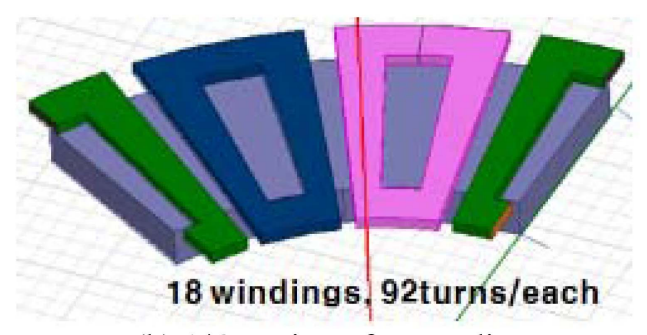

(b) $1 / 6$ section of stator disc

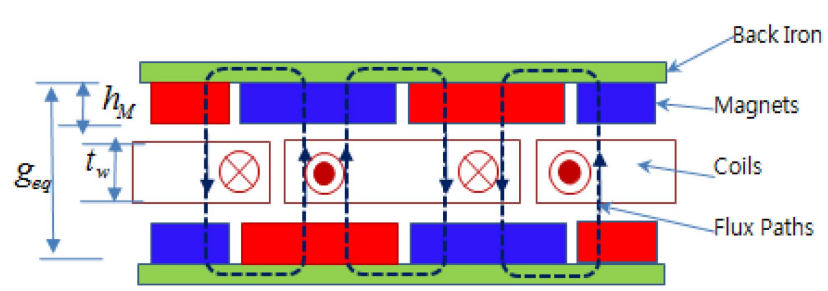

(c) Geometry and flux paths in air-gap

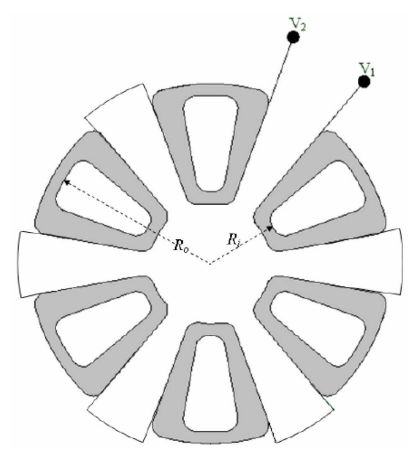

(d) Trapezoidal winding

Fig. 3. (Color online) Geometry model of coreless AFPM machine with trapezoidal windings. flux density is flat and constant in the radial direction. Considering three-phase machine with 18 windings in a section of 360 electrical degrees, the magnetic circuit of one flux loop consists of one and a half windings on each side of the stator, facing permanent magnets embedded in the rotor. The magnetic circuit model for one electrical period for a half-side of the motor is expressed in terms of the air-gap reluctances, stator magneto-motive forces, and fluxes through the magnetic circuit [1].

The magnetic flux excited by the PMs per pole is defined in the literature [1] by Eq. (1).

$$
\begin{aligned}
\Phi_{f}= & \int_{R_{\text {in }}}^{R_{\text {out }}} \alpha_{i} B_{m g} \frac{2 \pi}{2 p} r d r=\alpha_{i} B_{m g} \frac{\pi}{2 p}\left(R_{o}^{2}-R_{i}^{2}\right) \\
& =\alpha_{i} B_{m g} \frac{\pi}{8 p} D_{o}^{2}\left(1-k_{d}^{2}\right)
\end{aligned}
$$

where $\alpha_{i}$ is the ratio of the average flux density $B_{\text {avg }}$ to peak value of the magnetic flux density $B_{m g}$ in the air-gap, $p$ is the number of pole pairs, $R_{i}=0.5 D_{i}$ and $R_{o}=0.5 D_{o}$ are the inner and outer radii of the PMs, and $k_{d}=R_{i} / R_{o}=$ $D_{i} / D_{o}$ is the PM diameter ratio, respectively.

The equivalent air-gap of the coreless AFPM machine in Fig. 3(c) is given by Eq. (2).

$$
g_{e q}=2\left(g+0.5 t_{w}+\frac{h_{M}}{\mu_{\text {rrec }}}\right)
$$

where $g$ is the air-gap clearance, $t_{w}$ is the stator winding axial thickness, $h_{M}$ is the axial height of the PM and $\mu_{\text {rrec }}$ is the relative recoil permeability of the PM.

\subsubsection{Stator Winding Design}

A single-layer, non-overlapping type of winding, called a "trapezoidal winding" as shown in Fig. 3, was adopted in this design because of its ease of fabrication and assembly. The assembly of the stator is made possible by bending the end of the coils by a certain amount, so that the active conductors lie evenly within the same plane and the end windings nestle closely together. The windings are held in position by using a composite material of epoxy resin and hardener. The distribution factor of the windings for the fundamental space harmonic [1] is given by Eq. (3).

$$
k_{g 1}=\frac{\sin \left(\frac{\pi}{2 m_{1}}\right)}{z \sin \frac{\pi}{2 m_{1} z}}
$$

where $m_{1}$ is the number of phases and $z$ is the coil phase belt as determined from, and $z=Q_{c} / m_{1} F$ is the number of stator coils. $F$ is the coil factor that is deter- 
mined by taking the greatest common divider (GCD) of the number of poles and coils $\left(F=G C D\left(20, Q_{c}\right)\right)$. The pitch factor of the windings for the fundamental space harmonic is calculated using Eq. (4).

$$
k_{p 1}=\sin \left(\frac{\pi}{2} \frac{2 p}{s_{1}}\right) \frac{\sin \frac{\theta_{r e}}{2}}{\frac{\theta_{r e}}{2}}=\sin \left(\frac{\theta_{m}}{2}\right) \frac{\sin \frac{\theta_{r e}}{2}}{\frac{\theta_{r e}}{2}}
$$

where $\theta_{m}=2 \pi p / s_{1}$ is the slot pitch angle, and $\theta_{r e}$ is the electrical angle corresponding to the coil-layer width. Accordingly, the winding factor for a single-layer nonoverlap winding is the product of the distribution factor and the pitch factor, i.e.:

$$
k_{\omega 1}=k_{d 1} \cdot k_{p 1}
$$

Then pole pitch is 180 electrical degrees in angle and the coil pitch is between a minimum of 120 and a maximum of 240 electrical degrees. Accordingly the induced EMF in each armature coil can be calculated based on the first harmonic of the flux density as:

$$
e_{f}=N_{1} k_{\omega 1} \frac{d \Phi_{f 1}}{d t}=2 \pi f N_{1} k_{\omega 1} \Phi_{f} \cos \omega t
$$

where $\Phi_{f 1}=\Phi_{f} \sin \omega t$ is the magnetic flux waveform, $N_{1}$ is the number of turns in series per phase, and $f$ is the angular frequency, respectively. The rms value is obtained by dividing the peak value of the EMF by $\sqrt{2}$.

$$
E_{f}=\sqrt{2} \pi f N_{1} k_{\omega 1} \Phi_{f}=\sqrt{2} \pi p N_{1} k_{\omega 1} \Phi_{f} n_{s}=k_{E} n_{s}
$$

where $k_{E}=\sqrt{2} \pi N_{1} \Phi_{f}$ is the EMF constant and $n_{s}$ is the rotational speed. Assuming that at the axial middle of the stator the flux distribution generated by the armature coils with current excitations assumes a 'conical' shape, as has been reported in the literature $[1,5]$. Therefore, the flux density is presumed to be constant over the center of the circular coil and to decrease linearly across the coil. However, a substantial leakage flux is detected around the coils because of the relatively large air-gap, which can be accounted for by using a leakage flux compensation factor $k_{L}=1.5$. Consequently, the coil inductance can be evaluated using Eq. (8).

$$
L=\frac{k_{L} \mu_{0} \pi N_{1}^{2}}{6\left(g_{e q}+2 l_{m}\right)}\left(3 R_{i}^{2}+2 R_{i} R_{o}+R_{o}^{2}\right)
$$

where $\mu_{0}$ is the vacuum permeability, and $R_{i}, R_{o}$ are the circular winding inner and outer radii in Fig. 3(d), respectively. The required minimum average torque developed by the machine is given by Eq. (9).

$$
T_{r}=\frac{m_{1}}{\sqrt{2}} p N_{1} k_{\omega 1} \Phi_{f} I_{a}=k_{T} I_{a}
$$

where $k_{T}=\frac{m_{1}}{\sqrt{2}} p N_{1} k_{\omega 1} \Phi_{f}$ is the torque constant.

The machine torque density and power density for the total volume can be defined by Eq. (10) and (11), respectively.

$$
\begin{aligned}
& T_{d}=\frac{T_{r}}{\pi / 4 D_{t}^{2} L_{t}}=\frac{T_{r}}{\omega_{m} \frac{\pi}{4} D_{t}^{2} L_{t}} \\
& P_{d}=\frac{\omega_{m} T_{r}}{\pi / 4 D_{t}^{2} L_{t}}=\frac{P_{r}}{\frac{\pi}{4} D_{t}^{2} L_{t}}
\end{aligned}
$$

where $D_{t}$ is the total outer diameter of the machine including the stack outer diameter and the protrusion of the end windings from the iron stack in the radial direction, $L_{t}$ is the total length of the machine including the stack length and the protrusion of the end winding from the iron stack in the axial direction, and $\omega_{m}$ is the rotor angular speed.

\subsection{Design Requirements}

Regardless of the efficiency of the computer software, it is always important to check the overall performance and design requirements. The number of poles is mainly determined by considering the rotational speed of the rotor and the magnet material and grade. Because of poor magnet and space utilization, a machine with a small number of magnet poles would have a much larger diameter than a machine with a larger number of poles but

Table 1. Parameters of analysis model for candidate design.

\begin{tabular}{clcc}
\hline \hline Items & \multicolumn{1}{c}{ Parameters } & Unit & Values \\
\hline \multirow{4}{*}{ Stator } & Average air-gap & $\mathrm{mm}$ & 1.0 \\
& No. of windings & ea & 18 \\
& Outer diameter & $\mathrm{mm}$ & 450 \\
& Inner diameter & $\mathrm{mm}$ & 285 \\
& Coils in each winding & turns & 92 \\
\hline \multirow{5}{*}{ Rotor } & No. of magnets & ea & 24 \\
& Outer diameter & $\mathrm{mm}$ & 450 \\
& Inner diameter & $\mathrm{mm}$ & 280 \\
& Rotor speed & $\mathrm{rpm}$ & 300 \\
\hline \multirow{5}{*}{ General } & Rated voltage & $\mathrm{V}$ & 288 \\
& Frequency & $\mathrm{Hz}$ & 120 \\
& Phase & $\mathrm{ea}$ & 3 \\
& Output power & $\mathrm{W}$ & 2,000 \\
\hline \multirow{2}{*}{ Misc. } & Temperature rise limits & ${ }^{\circ} \mathrm{C}$ & 75 \\
& Speed range & $\mathrm{rpm}$ & 200 to 800 \\
\hline
\end{tabular}


the same power output. Thus, it is necessary to consider a configuration with a larger number of poles, which would increase the eddy current losses and the assembly complexity.

The design requirements for this application are summarized in Table 1. A configuration with 24 poles and 18 windings is chosen because it offers better magnet utilization with a smaller rotor diameter. Moreover, small, stranded wires are used to minimize the eddy current losses. Based on our analytical calculations, a generator is sized and designed to develop $2 \mathrm{~kW}$ at a rated speed of $300 \mathrm{rpm}$, using off-the-shelf magnets to reduce the prototype cost.

\section{FE Analysis and Design Optimization}

\subsection{FE Analysis Model}

The modeling process consisted of design calculations and FEA to predict the performance of the candidate designs. The dimensions and materials were selected using the design and modeling procedure proposed by Miller [9,14]. By applying Galerkin's method to the magnet vector potential in the magnetic circuits, the FEA for the machine is not required to solve this analytically [15]. Rather, the commercially available Maxwell 3D software incorporates tools that can achieve this. The FEA was used to confirm the magnet circuit saturation, as well as to obtain the back EMF and to calculate the winding inductances and electromagnetic torque during dynamic simulation to enable a more accurate design cycle. Figure 4 shows partial mesh results for the FE analysis of a physical model of the candidate machine. Given the symmetry of an AFPM machine, each half of the machine, relative to the center plane, mirrors the other half in the axial direction. Thus, it is possible to model only one-sixth of the machine comprising the rotor disk, the air-gap clearance, and the stator, as shown in Fig. 4.

\subsection{Design Optimization}

Generally, in the design of an AFPM machine, the dimensional equations for the machine are related to the choice of the objective functions [16]. Here, in the design of the proposed generator, the main goal is to maximize the output power density and ensure the maximum possible efficiency while ensuring a rated output power, acceptable current density, and desired phase voltage.

Objective function in the design optimization with the constraints was defined by Eq. (12). To achieve this goal of maximizing the power density, the variables are carefully chosen by Eq. (13).

\section{Maximize $\left[P_{d}\right]$}

$$
\text { subject to }\left\{\begin{array}{c}
\eta(\bar{x}) \geq \eta_{0} \\
P(\bar{x}) \geq P_{0} \\
J(\bar{x}) \leq J_{a} \\
V(\bar{x}) \leq V_{a}
\end{array}\right.
$$

$$
\bar{x}=\left(k_{d}, h_{M}, t_{w}, g\right)
$$

where $P_{d}$ is the output power density, $\eta_{0}$ is the machine's desired minimum efficiency, $P_{o}$ is the rated output power, $J_{a}$ is the maximum allowable current density, $V_{a}$ is the maximum rms phase voltage at the rated power, $k_{d}=R_{i} /$ $R_{o}=D_{i} / D_{o}$ is the of rotor disc inner and outer radius, $h_{M}$ is the PM thickness, $t_{w}$ is the stator winding thickness, and $g$ is the air-gap clearance, respectively.

The optimization algorithm of incomplete Choleski conjugate gradient method (ICCG iterative solver) [17]

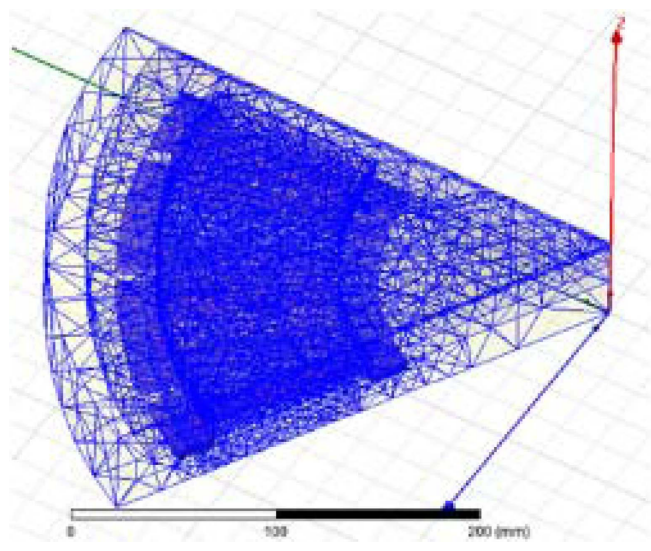

Fig. 4. (Color online) 1/6 Meshed model of the machine.

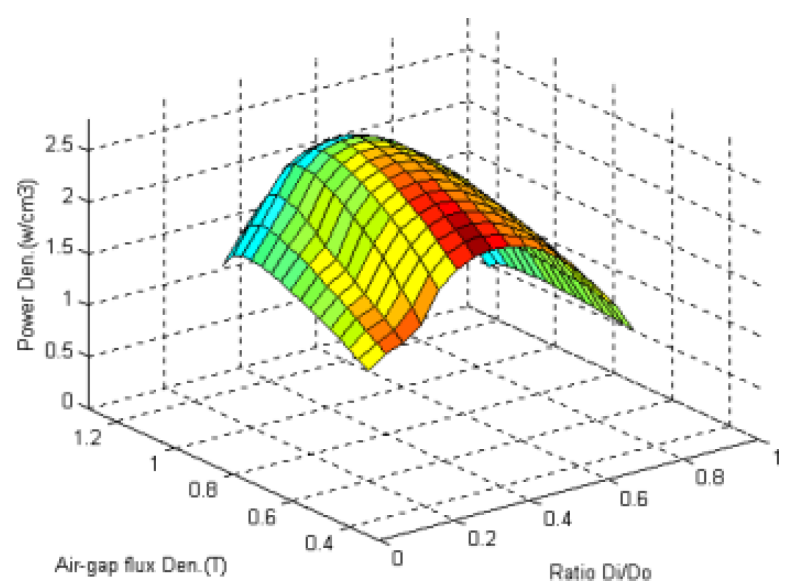

Fig. 5. (Color online) Power density plot as a function of airgap flux density $\left(B_{g}\right)$ and diameter ratio $\left(k_{d}\right)$. 


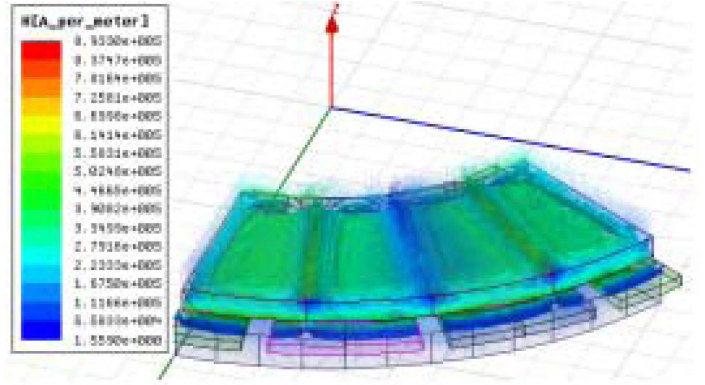

(a) Flux density of the $1 / 6$ Model

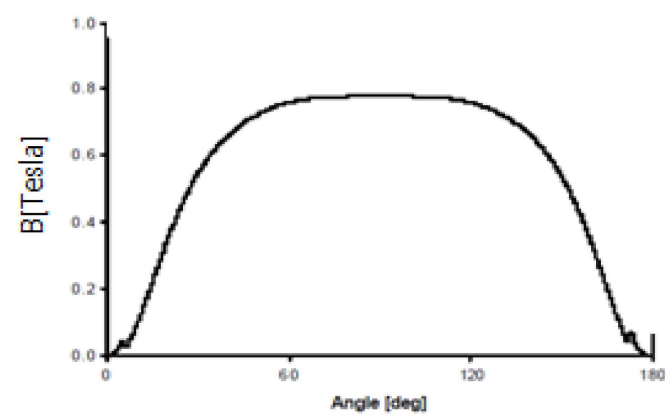

(b) Distribution of flux density in the air-gap

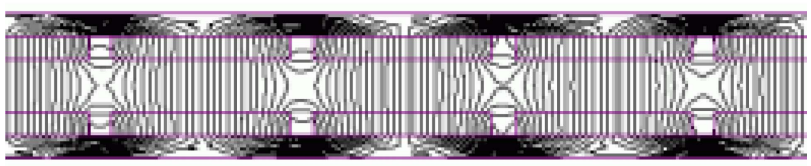

(c) Distribution of flux lines in the air-gap

Fig. 6. (Color online) Magnetic flux distribution obtained by FEA.

was used for this solution. Figure 5 shows a power density plot as a function of the air-gap flux density obtained from the variables and the ratio $k_{d}$ for the machine. This plot shows that the maximum power density (or torque density), which is found to be $2.56 \mathrm{~W} / \mathrm{cm}^{3}$, occurs at an air-gap flux density of $1.05 \mathrm{~T}$ and a diameter ratio of $k_{d}=$ 0.63 . At the maximum point, the machine efficiency is 94.3\%. Likewise, the maximum power density point can be obtained. The results, along with the other parameters of the designed machine, are also listed in Table 1.

\subsection{Magnetic Flux Distribution and Generated Power}

The candidate design for the machine was verified according to the flux-linkage versus rotational speed characteristics at the aligned positions. Figures 6(a) shows the flux density in the PMs and the windings of a onesixth model. Figures 6(b) and (c) show the distribution of magnetic flux density and flux lines in the air-gap, respectively. The flux patterns are similar but all the flux paths obtained by the FEA emanate at right angles to the

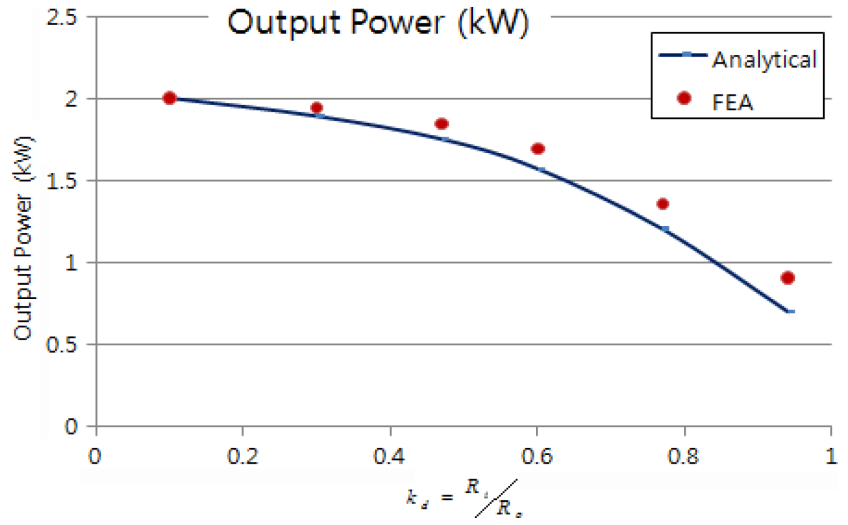

Fig. 7. (Color online) Power outputs as obtained by analytical and FEA methods.

pole surface. This was expected from the FEA because of the imposed constant surface potential and pole surface, with the magnets virtually in contact, indicate a strong magnetic field with a significantly large radial component, especially in close proximity to the pole surface. The radial component of the air-gap magnetic field is a very good indication of the shape of the back EMF voltages generated at the machine terminals. Since the EMF and inductance of the coil can be computed accurately by the 3D FEA model, machine performance prediction and design optimization can be achieved with confidence.

The generated power and EMF obtained by the analytical and FEA methods are illustrated in Figures 7 and 8, respectively. It can be seen that the analytically obtained power outputs gradually become smaller than the FEA values when $R_{i}$ is increasing as shown in Fig. 7. This can be explained by the EMF errors between the two methods as shown in Fig. 8. Consequently, a larger flux enhancement factor is highly desirable for the accurate prediction of the machine performance, because of the greater impact of the non-sinusoidal radial components on increasing $R_{i}$. Figure 8 also shows that the inductance errors between

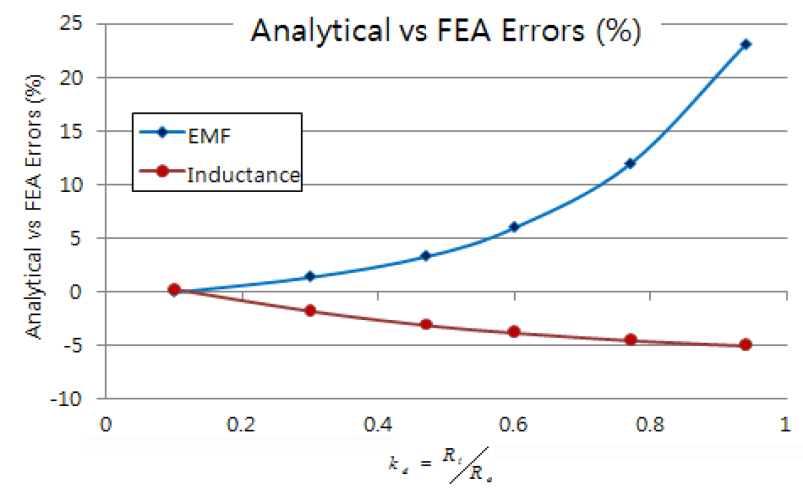

Fig. 8. (Color online) EMF errors between analytical and FEA methods. 
two methods are much more stable and smaller than those for the EMF. It should be noted that the power output of the machine will first gradually increase and then decrease as $R_{i}$ increases and that the analytical and FEA results are in reasonable agreement.

\subsection{FEA Simulation Results}

An FEA time transient simulation was performed using the available design and simulation tools [14]. Figure 9(a) shows the waveform of the EMF induced in the armature coils and terminal voltage for each phase. The EMF and terminal voltages for each phase at rated speed of 300 rpm are approximately $300 \mathrm{~V}$ and $288 \mathrm{~V}$ in the peak,

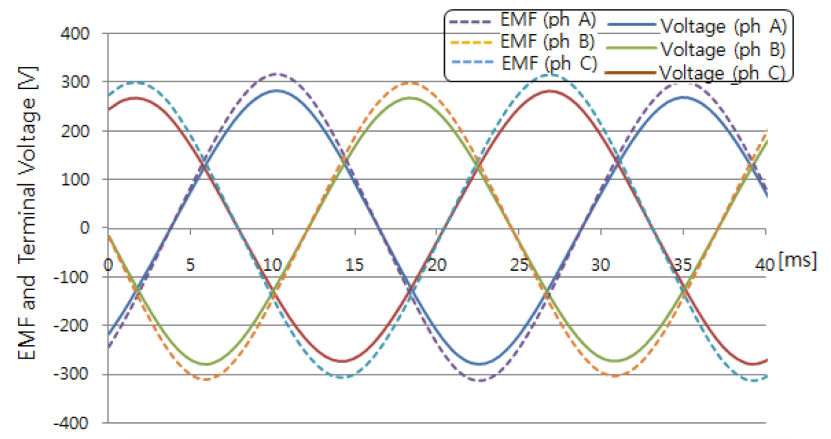

(a) Waveform of EMF and terminal voltage

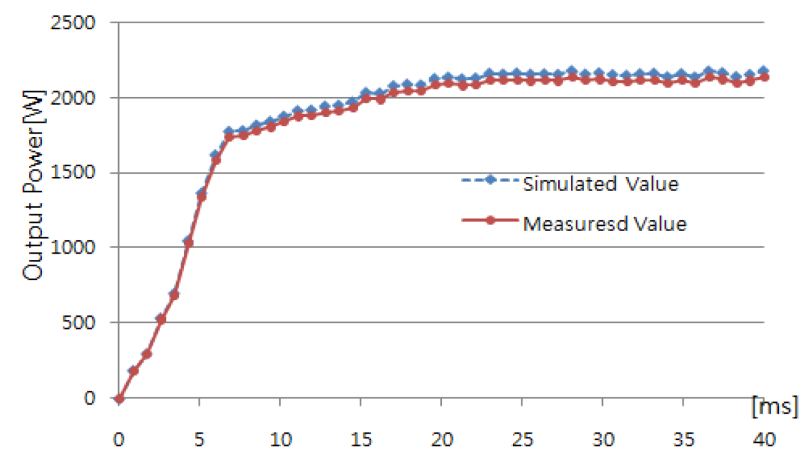

(b) Time response of output power

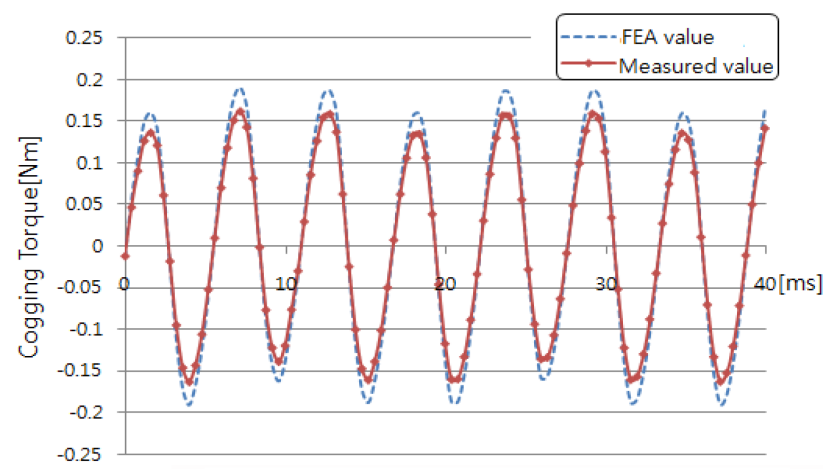

(c) Time response of cogging torque

Fig. 9. (Color online) FEA simulation and measured values at rated speed $(300 \mathrm{rpm})$. respectively. Figure 9(b) shows the time response of the electromagnetic output power of $2 \mathrm{~kW}$ of which value approaches nearly the output power of generator as seen in Fig. 12(c). Figure 9(c) shows that the cogging torque, caused by magnetic saturation in the rotor steel shell, exists even when there is no stator current in the nonoperating state.

\section{Prototyping and Testing of the Machine}

Based on the aforementioned design data, a prototype generator, as shown in Fig. 10, was fabricated for testing to verify the optimized design and performance. The nonferromagnetic holder is shown in Fig. 10. This holder is attached to the rotor disc with screws. These screws prevent the magnets from moving while the generator is

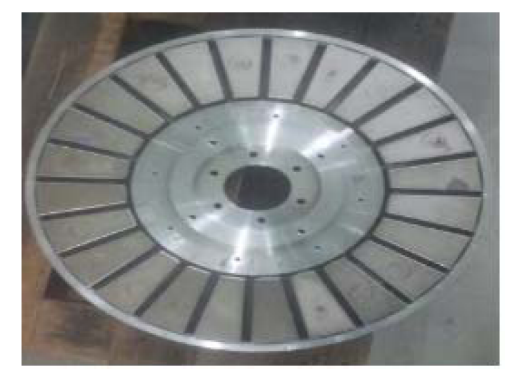

(a) PM rotor

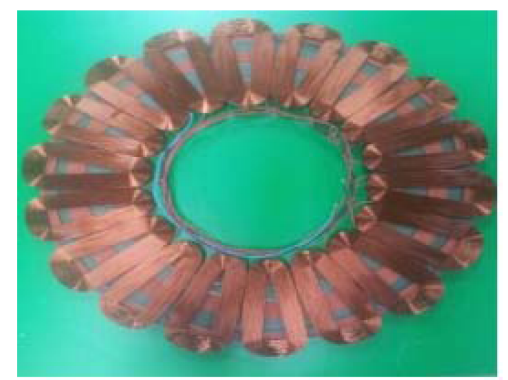

(b) Coreless windings

Fig. 10. (Color online) Prototype coreless AFPM machine.

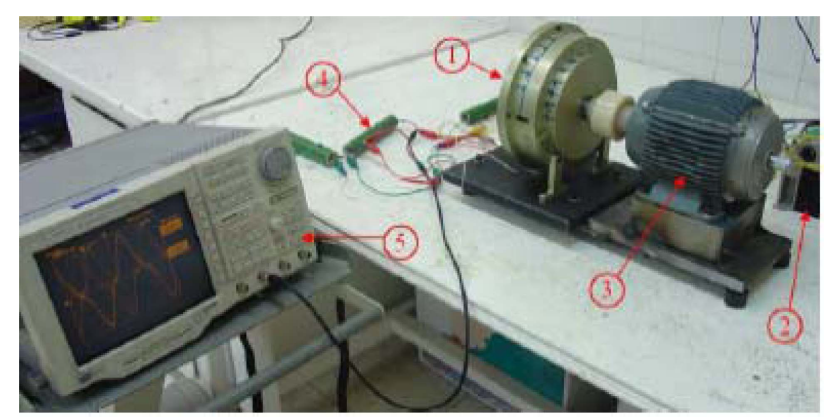

Fig. 11. (Color online) Test setup consisting of (1) Constructed generator, (2) Converter, (3) 3-phase induction machine, (4) Resistive load, and (5) Oscilloscope. 


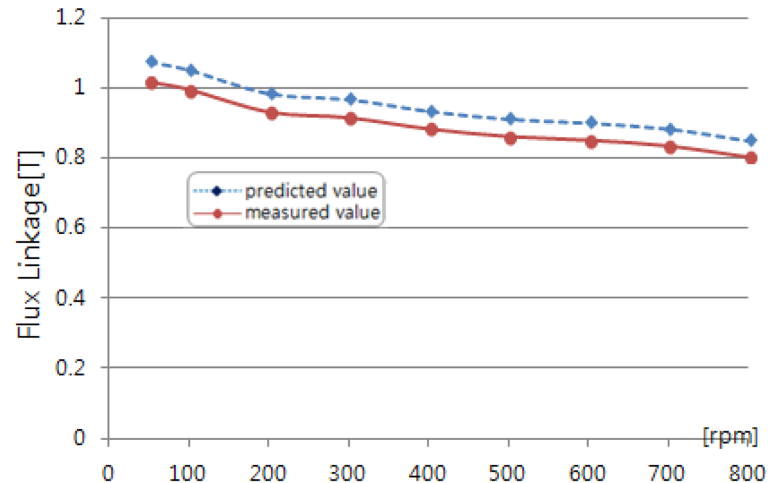

(a) Linkage flux level

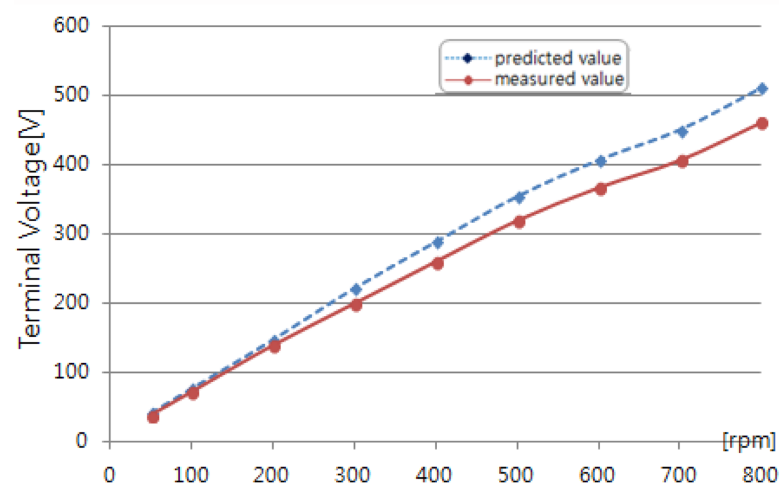

(b) Terminal voltage

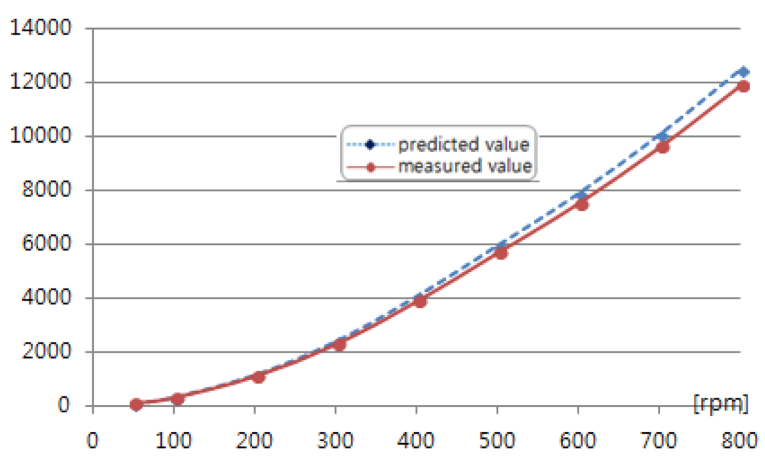

(c) Output power

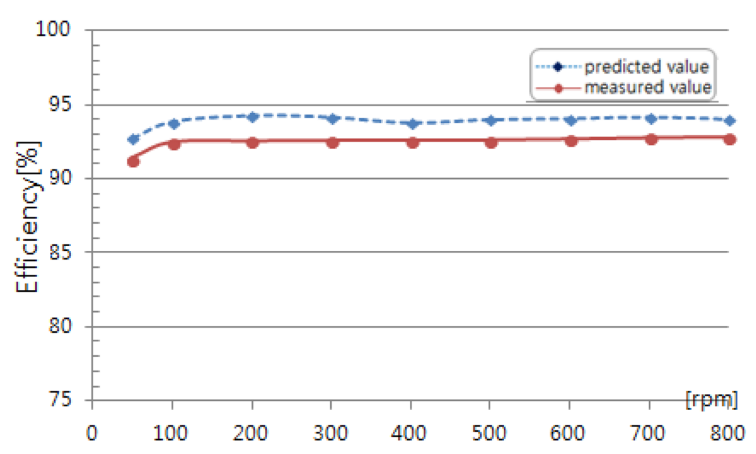

(d) Efficiency

Fig. 12. (Color online) Prototype test result at different rotating speed.
Table 2. Test results for prototype machine.

\begin{tabular}{lccc}
\hline \hline \multicolumn{1}{c}{ Items } & Units & $\begin{array}{c}\text { Predicted } \\
\text { value }\end{array}$ & $\begin{array}{c}\text { Measured } \\
\text { value }\end{array}$ \\
\hline Frequency & $\mathrm{Hz}$ & 120 & 120 \\
Rated speed & $\mathrm{rpm}$ & 300 & 300 \\
Terminal Voltage & $\mathrm{V}$ & 221 & 200 \\
EMF constant & $\mathrm{V} / 1000 \mathrm{rpm}$ & 1,000 & 1000 \\
Output Power & watts & 2,396 & 2,284 \\
Efficiency & $\%$ & 94.3 & 92.6 \\
\hline
\end{tabular}

rotating. Rare-earth sintered $\mathrm{NdFeB}$ magnets are used, which have a remanent flux density of $0.46 \mathrm{~T}$, and a maximum allowable working temperature of around 130 ${ }^{\circ} \mathrm{C}$. There are eighteen 3-phase coils that are connected in series, as described in Table 1. Each coil consists of 92 turns of $1.03 \mathrm{~mm}$ diameter wire.

Performance tests on the prototype AFPM machine were carried out in the laboratory, and the results were analyzed. The tests focused on power generation, including terminal voltage, output power, and efficiency. A reconfigurable water-cooled bank of resistors was configured into a balanced three-phase load and then connected across the AFPM machine terminals. An induction machine was used as the prime mover. Figure 11 shows the experimental setup used for the tests.

The 3D FEA and measured values are compared and discussed. Figure 12(a) and (b) shows the flux linkage level and terminal voltage in the air-gap at different speeds, respectively. The terminal voltage increases linearly with the speed but the flux level remains constant. Figure 12(c) and (d) show the variations in the measured output powers and the efficiency at different speeds, respectively. The efficiency approaches $94.2 \%$ at $300 \mathrm{rpm}$. Because there are no core losses, the efficiency of the coreless machine is higher than that of an iron-core machine normally less than $90 \%[1,7,8,11]$. The fabricated generator is relatively small. Figure 12 clearly shows that, with an increase in speed, the efficiency of the machine increases, but this is not necessarily true for a machine with an iron core. The test results obtained for the generator are listed in Table 2.

\section{Conclusion}

Since the overall performance of a wind power generation system depends largely on the conversion efficiency of the power generator, a coreless AFPM generator is proposed that can be easily integrated into a wind turbine for low-speed applications. The AFPM generators of direct-drive small wind turbines are usually driven at relatively low speeds. Therefore, to increase the output 
power, a great number of pole-pairs are needed. At these low speeds, the output power increases, so there is no need to use more magnets to increase the number of polepairs. Coreless configurations feature no ferromagnetic material, as they are subject to much lower structural loads and thus have no need for steel laminations in the stator. This eliminates the associated eddy currents and hysteresis core losses. They all have a lower cogging torque and make less noise while operating. Given the absence of core losses, a coreless-stator AFPMG machine operates at a higher efficiency than a conventional machine, regardless of the rotational speed [18-20]. In addition, the machine can be made smaller and is cheaper to manufacture.

The FE analysis gave results that are acceptable agreement with the design optimization, as regards the air-gap flux density, the induced phase voltage, the output power, and the cogging torque. The results of our comparison demonstrate that the proposed generator has a number of advantages such as a simpler structure, higher efficiency over a wide range of operating speeds, higher energy yield, lighter weight and better power utilization than conventional machines. This proposed design method will be applied to multiple-rotor AFPM machines together with other variable technologies further.

\section{References}

[1] F. J. Gieras, R. J. Wang, and M. J. Kamper, Axial Flux Permanent Magnet Brushless Machines, Springer, 2nd edition, 304 (2008).

[2] E. Muljadi, C. P. Butterfield, and Yih-huie Wan, IEEE Trans. Ind. Appl. 35, 831 (1999).

[3] N. F. Lombard and M. J. Kamper, IEEE Trans. Energy Conversion 14, 1051 (1999).

[4] R. J. Wang, M. J. Kamper, K. V. D. Westhuizen, and J. F. Gieras, IEEE Trans. Magn. 41, 55 (2005).

[5] U. K. Madawala and J. T. Boys, IEEE Trans. Magn. 41,
2384 (2005).

[6] H. C. Lovatt, V. S. Ramsden, and B. C. Mecrow, Proc. Inst. Electr. Eng. Electr. Power Appl. 145, 402 (1998).

[7] R. J. Hill-Cottingham, P. C. Coles, J. F. Eastham, F. Profumo, A. Tenconi, and G. Gianolio, Proc. 36th IEEE Ind. Appl. Conf. 1634 (2001).

[8] R. J. Hill-Cottingham, P. C. Coles, J. F. Eastham, F. Profumo, A. Tenconi, and G. Gianolio, Proc. 37th IEEE Ind. Appl. Conf. 1274 (2002).

[9] T. J. E. Miller, Design of Brushless Permanent Magnet Machines, University of Glasgow, UK, Magna Physics Publishing and Clarendon Press, Oxford (1994).

[10] F. Caricchi, F. Crescimbini, and E. Santini, IEEE Trans. Ind. Appl. 31, 1062 (1995).

[11] R. J. Hill-Cottingham, P. C. Coles, J. F. Eastham, F. Profumo, A. Tenconi, and G. Gianolio, IEEE Trans. Magn. 38, 3003 (2002).

[12] W. Fei, P. C. K. Luk, J. Jinupun, Proc. IET Power Electronics, Machines and Drives Conf. 623 (2009).

[13] D.-W. Chung, Trans. of KIEE 61, 1820 (2012).

[14] K. C. Kim and S. K. Lee, Maxwell 2D/3D Training Manual for User Applications, Ansoft Co. User Group, Seoul, Korea, 1234 (2006).

[15] R. Wang, H. Mohellebi, T. J. Flack, M. J. Kamper, J. Buys, and M. Feliachi, IEEE Trans. Magn. 38, 1357 (2002).

[16] J. F. Gieras, and M. Wing, New York: Marcel Dekker Inc. 242 (1997).

[17] Maxim Naumov, Incomplete-LU and Cholesky Preconditioned Iterative Methods Using CUSPARSE and CUBLAS, NVIDIA CUSPARSE and CUBLAS Libraries, http://www.nvidia.com/object/cuda develop.html

[18] A. Di Napoli, F. Caricchi, F. Crescimbini, and G. Noia, Proc. International Conference on the Evolution and Modern Aspects of Synchronous Machine August (1991).

[19] E. Spooner and B. J. Chalmers, IEE Proc. B 139, 497 (1992).

[20] H. G. Kim, Y. T. Seo, and D. K. Lee, Proc. ICEE2002 941 (2002). 